\title{
THE CROSSING NUMBER OF CARTESIAN PRODUCT OF 5-WHEEL WITH ANY TREE
}

\author{
YuXI WANG AND YUANQIU Huang ${ }^{1}$ \\ College of Mathematics and Statistics \\ Hunan Normal University \\ Changsha, Hunan 410081, P.R. China \\ e-mail: wangyuxi19931282@163.com \\ hyqq@hunnu.edu.cn
}

\begin{abstract}
In this paper, we establish the crossing number of join product of 5wheel with $n$ isolated vertices. In addition, the exact values for the crossing numbers of Cartesian products of the wheels of order at most five with any tree $T$ are given.
\end{abstract}

Keywords: drawing, crossing number, join product, Cartesian product.

2010 Mathematics Subject Classification: 05C10, 05C38.

\section{REFERENCES}

[1] J.A. Bondy and U.S.R. Murty, Graph Theory with Applications (North-Holland, NewYork-Amsterdam-Oxford, 1982).

[2] D. Bokal, On the crossing numbers of Cartesian procucts with paths, J. Combin. Theory Ser. B 97 (2007) 381-384. doi:10.1016/j.jctb.2006.06.003

[3] D. Bokal, On the crossing numbers of Cartesian products with trees, J. Graph Theory 56 (2007) 287-300. doi:10.1002/jgt.20258

[4] Z. Ding and Y. Huang, The crossing numbers of join of some graphs with $n$ isolated vertices, Discuss. Math. Graph Theory 38 (2018) 899-909. doi:10.7151/dmgt.2048

[5] P. Erdős and R.K. Guy, Crossing number problems, Amer. Math. Monthly 80 (1973) 52-58. doi:10.1080/00029890.1973.11993230

\footnotetext{
${ }^{1}$ Corresponding author.
} 
[6] M.R. Garey and D.S. Johnson, Crossing number is NP-complete, SIAM J. Algebr. Discrete Methods 4 (1983) 312-316. doi: $10.1137 / 0604033$

[7] P.T. Ho, The crossing number of $K_{1, m, n}$, Discrete Math. 308 (2008) 5996-6002. doi:10.1016/j.disc.2007.11.023

[8] Y. Huang and T. Zhao, The crossing number of $K_{1,4, n}$, Discrete Math. 308 (2008) $1634-1638$. doi:10.1016/j.disc.2006.12.002

[9] S. Jendrol and M. Ščerbová, On the crossing numbers of $S_{m} \square P_{n}$ and $S_{m} \square C_{n}$, Časopis Pro Pěst. Mat. 107 (1982) 225-230.

[10] D.J. Kleitman, The crossing number of $K_{5, n}$, J. Combin. Theory 9 (1970) 315-323. doi:10.1016/S0021-9800(70)80087-4

[11] M. Klešč, The crossing numbers of products of path and stars with 4-vertex graphs, J. Graph Theory 18 (1994) 605-614. doi:10.1002/jgt.3190180608

[12] M. Klešč, The join of graphs and crossing numbers, Electron. Notes Discrete Math. 28 (2007) 349-355. doi:10.1016/j.endm.2007.01.049

[13] M. Klešč, The crossing numbers of join of the special graph on six vertices with path and cycle, Discrete Math. 310 (2010) 1475-1481. doi:10.1016/j.disc.2009.08.018

[14] M. Klešč and Š. Schrötter, The crossing numbers of join products of paths with graphs of order four, Discuss. Math. Graph Theory 31 (2011) 321-331. doi:10.7151/dmgt.1548

[15] M. Klešč and Š. Schrötter, The crossing numbers of join of paths and cycles with two graphs of order five, Lecture Notes in Comput. Sci. 7125 (2012) 160-167. doi:10.1007/978-3-642-28212-6_15

[16] M. Klešč, J. Petrillová and M. Valo, On the crossing numbers of Cartesian products of wheels and trees, Discuss. Math. Graph Theory 37 (2017) 399-413. doi:10.7151/dmgt.1957

[17] Z. Ma and J. Cai, The Crossing Number of $W_{5} \times S_{n}$, Acta Math. Appl. Sin. 31 (2008) 616-623, in Chinese.

[18] H. Mei and Y. Huang, The crossing number of $K_{1,5, n}$, International J. Math. Combin. 39 (2002) 1-6.

[19] K. Zarankiewicz, On a problem of P. Turán concerning graphs, Fund. Math. 41 (1955) 137-145.

doi:10.4064/fm-41-1-137-145

Received 19 September 2017

Revised 1 September 2018

Accepted 3 September 2018 